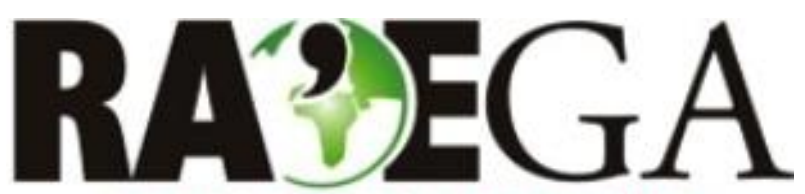

O ESPAÇO GEOGRÁFICO EM ANÁLISE

\title{
USO E COBERTURA DA TERRA NO TERRITÓRIO AYAHUASQUEIRO EM RONDÔNIA: UMA ANÁLISE DE ARRANJOS INSTITUCIONAIS POR CLASSIFICAÇÃO ORIENTADA A OBJETO ${ }^{1}$
}

\section{USE AND COVERAGE OF THE EARTH IN THE AYAHUASCA TERRITORY IN RONDÔNIA: AN ANALYSIS OF INSTITUTIONAL ARRANGEMENTS BY OBJECT-ORIENTED CLASSIFICATION}

\author{
Julien Marius Reis Thevenin ${ }^{2}$, Edson Luís Piroli ${ }^{3}$
}

RESUMO

Diante dos problemas ligados às mudanças no uso e na cobertura da terra, em especial ao desflorestamento da Amazônia, e da busca por padrões institucionais de conservação florestal é que se inicia esta pesquisa. Desse modo, analisa-se o uso e a cobertura da terra dos territórios religiosos de organizações que têm por prática o uso do chá Ayahuasca em seus rituais em Rondônia-BR. Para o mapeamento foram utilizadas imagens do satélite QuickBird extraídas do Google Earth por meio do aplicativo El-Shayal, em resolução espacial de 1,42 m. Utilizando-se do aplicativo Envi 5.0 foram realizadas classificações orientadas a objeto, que posteriormente foram corrigidas manualmente no aplicativo ArcGIS $10 \mathrm{com}$ base em fotointerpretação e observações realizadas em campo. A necessidade que essas religiões têm de cultivar as espécies Banisteriopsis caapi e Psychotria viridis para o autoconsumo do chá Ayahuasca e o reconhecimento por parte dessas instituições de que essas plantas precisam do ambiente florestal para um melhor desenvolvimento contribuíram para que a expansão territorial ayahuasqueira tenha se vinculado ao crescimento e manutenção de áreas florestadas e de agrofloresta. Tal afirmação foi evidenciada nos resultados, nos quais $92,5 \%$ da soma das áreas analisadas permanecem com cobertura arbórea em estágios intermediários ou avançados de sucessão, mesmo sob o efeito de borda que sofrem em função do grande número de pastagens no entorno, e com percentuais que superam os exigidos pelas normas ambientais vigentes.

Palavras-chave: Ayahuasca; conservação florestal; Reserva Legal; Amazônia; religião

\section{ABSTRACT}

Faced with the problems related to the changes in land use and land cover, especially the deforestation of the Amazon, and the search for institutional patterns of forest conservation, this research is initiated. Thus, the use and coverage of the land of the religious territories of organizations that practice the use of Ayahuasca tea in its rituals in Rondônia-BR is analyzed. For the mapping, images of the QuickBird satellite extracted from Google Earth were used through the El-Shayal application, in spatial resolution of $1.42 \mathrm{~m}$. Using the Envi 5.0 application, objectoriented classifications were performed, which were later manually corrected in the ArcGIS 10 application based on photointerpretation and field observations. The need for these religions to cultivate the species Banisteriopsis caapi and Psychotria viridis for the self-consumption of Ayahuasca tea, and the recognition by these institutions that these plants need the forest environment for better development have contributed to the Ayahuasca territorial expansion linked to the growth and maintenance of forested areas and agroforestry. This statement was evidenced in the results, in which $92,5 \%$ of the sum of the analyzed areas remain with tree cover in intermediate or advanced stages of succession, even under the border effect that they suffer due to the large number of pastures in the surroundings, and with percentages that exceed those required by current environmental standards.

Key-words: Ayahuasca; Forest conservation; Legal Reserve; Amazônia; religion

Recebido em: 02/05/2017

Aceito em: 09/02/2018

\footnotetext{
${ }^{1}$ Os autores agradecem à Fundação de Amparo de Pesquisa do Estado de São Paulo, processo no 2013/02207-1 FAPESP, pelo apoio financeiro na forma de bolsa de doutorado, que viabilizou a realização desse trabalho.

2 Universidade Estadual Paulista, Presidente Prudente/SP, e-mail: julienreis@gmail.com

3 Universidade Estadual Paulista, Ourinhos/SP, e-mail: piroli@ourinhos.unesp.br
} 


\section{USO E COBERTURA DA TERRA NO TERRITÓRIO AYAHUASQUEIRO EM RONDÔNIA: UMA ANÁLISE DE ARRANJOS INSTITUCIONAIS POR CLASSIFICAÇÃO ORIENTADA A OBJETO}

\section{INTRODUÇÃO}

A riqueza da região amazônica transpõe a sua biodiversidade, sem deixar de vincular-se à floresta, estando também na abundância de suas águas, na regulação climática e sendo, além de tudo, cultural. Os serviços ecossistêmicos prestados por esse grande e rico bioma ao mundo são, até os dias atuais, imensuráveis. Devido à valorização econômica de seus recursos naturais (incluindo suas terras e seu subsolo), essa região foi considerada como um "vazio demográfico", tendo sido alvo de múltiplos interesses nacionais e internacionais (PORTOGONÇALVES, 2005).

A reocupação caótica das terras em Rondônia resultou não só num rápido processo de desflorestamento (SKOLE et al., 1997), mas levou a sérios conflitos entre colonos e comunidades indígenas, além da contínua invasão de unidades de conservação (BROWN, 1992). Após sucessivas frentes de ocupação, o estado de Rondônia tornou-se um dos três estados com as maiores taxas de desmatamento na Amazônia Legal, junto ao Mato Grosso e Pará.

Dados do INPE (2017) apontam que, em 56 anos (de 1960 a 2016), foram devastados $87.423,38 \mathrm{~km}^{2}$ de floresta em Rondônia, o que corresponde a uma redução aproximada de $40 \%$ da cobertura vegetal original, apenas nesse período. Essas taxas são ainda mais alarmantes em terras devolutas e propriedades privadas não protegidas, se considerarmos que, em dezembro de 2010, 42,7 \% (101.345 km²) do território de Rondônia já haviam sido transformados em áreas protegidas (21,6\% Unidades de Conservação e $21,0 \%$ Terras Indígenas), as quais possuem taxas menores de desmatamento (VERÍSSIMO et al., 2011).

Realidades como essas confirmam o histórico descumprimento do Código Florestal (sobretudo no tocante à Reserva Legal e Áreas de Preservação Permanente) nas propriedades privadas do país, especialmente no estado de Rondônia, onde a área de Reserva Legal na maioria das propriedades deveria cobrir $80 \%$ dos imóveis rurais, principalmente durante a vigência da Lei 4.771/1965.
É neste contexto que, nos estudos de mudança florestal, cada vez mais arranjos institucionais tem merecido atenção especial, uma vez que instituições efetivas de posse da terra têm potencial tanto para limitar a exploração florestal, como para encorajá-la, sendo amplamente reconhecidas como fundamentais para gestão florestal eficiente (TUCKER; SOUTHWORTH, 2009). Desse modo, instituições poderosas como as religiões têm importante papel, pois tanto podem afastar o homem da natureza, com posturas antinaturais, quanto podem aproximá-lo por meio da sacralização da natureza (SALATINO, 2001).

Assim, tendo em vista os problemas ligados às mudanças no uso e na cobertura da terra, em especial ao desflorestamento da Amazônia no estado de Rondônia, foram analisados os territórios religiosos de organizações que têm por prática o uso do chá Ayahuasca ${ }^{4}$ em seus rituais.

A necessidade que essas religiões têm de cultivar o cipó Banisteriopsis caapi, popularmente chamado de jagube ou mariri, e a folha Psychotria viridis, popularmente chamada de rainha ou chacrona, para o autoconsumo do chá Ayahuasca, bem como o reconhecimento por parte dessas instituições de que essas plantas precisam do ambiente florestal para um melhor desenvolvimento, estiveram no cerne desta pesquisa.

A partir disso e da busca por padrões institucionais de conservação florestal, estabeleceu-se o objetivo de analisar o uso e a cobertura da terra do território de religiões ayahuasqueiras no estado de Rondônia-BR. Para tal, o trabalho contou com técnicas de geoprocessamento incluindo observações sistemáticas em campo e classificação orientada a objeto, com detalhamento da fitofisionomia da vegetação.

\footnotetext{
4 Inúmeras são as denominações utilizadas para designar o chá Ayahuasca, como por exemplo: Hoasca, Daime, Vegetal, Cipó, Mariri, Yagé ou Kamarampi. Segundo Bernadino-Costa e Silva (2011) o termo Ayahuasca tem sido o mais utilizado na bibliografia acadêmica para se referir ao chá e às práticas culturais a ele relacionadas.
} 


\section{USO E COBERTURA DA TERRA NO TERRITÓRIO AYAHUASQUEIRO EM RONDÔNIA: UMA ANÁLISE DE ARRANJOS INSTITUCIONAIS POR CLASSIFICAÇÃO ORIENTADA A OBJETO}

Este chá tem sido utilizado há séculos por povos indígenas de diversos países que compõem a Amazônia. Com a liderança de seringueiros, nas primeiras décadas do século $X X$, a Ayahuasca passa a ser usada como sacramento em práticas que demonstram um sincretismo religioso de influência cristã, indígena e afrobrasileira em três vertentes principais: o Santo Daime ${ }^{5}$; a Barquinha ${ }^{6}$; a União do Vegetal $\left(U D^{7}\right)$; e por outras organizações religiosas que tiveram nessas a sua origem. Esses movimentos religiosos têm se expandido do Brasil para o mundo e apresentam novos paradigmas a serem desvendados pela ciência.

\footnotetext{
5 Movimento religioso iniciado nas primeiras décadas do século XX, no estado do Acre, por Raimundo Irineu Serra (Mestre Irineu), fundador do Centro de Iluminação Cristã Luz Universal - CICLU (Alto Santo), em Rio Branco. O termo também designa as diversas vertentes religiosas que surgiram posteriormente e que têm por base litúrgica os ensinamentos trazidos por Mestre Irineu.

${ }^{6}$ O termo refere-se aos segmentos religiosos que têm como base litúrgica os ensinamentos de Daniel Pereira Mattos (Mestre Daniel), fundador do Centro Espírita e Culto de Oração "Casa de Jesus - Fonte de Luz", no ano de 1945, na zona rural do município de Rio Branco - AC.

7 Centro Espírita Beneficente União do Vegetal - CEBUDV, criado em 1961 por José Gabriel da Costa (Mestre Gabriel), em meio à floresta, no seringal Sunta (entre o Acre e a Bolívia), e formalizado em 1964 quando Mestre Gabriel e sua família passaram a morar em Porto Velho - RO.
}

\section{MATERIAIS E MÉTODOS}

2.1. DELIMITAÇÃO DA ÁREA DE ESTUDO E PESQUISA DE CAMPO

Embora Thevenin (2017) tenha identificado 53 propriedades em cinco organizações religiosas que fazem uso do chá Ayahuasca em Rondônia, apenas 24 dessas são rurais, sendo que 23 pertencem ao Centro Espírita Beneficente União do Vegetal (CEBUDV) e 1 ao Centro de Irradiação Espiritual "Casa de Jesus e Lar de Frei Manoel ${ }^{8 \prime}$ (Mapa 1).

\footnotetext{
${ }^{8}$ Fundado em 1990, esse Centro tem como base litúrgica os ensinamentos de Daniel Pereira Mattos (Mestre Daniel), fundador do Centro Espirita e Culto de Oração "Casa de Jesus - Fonte de Luz"(conhecido popularmente como Barquinha), no ano de 1945, na zona rural do município de Rio Branco - Acre.
} 


\section{USO E COBERTURA DA TERRA NO TERRITÓRIO AYAHUASQUEIRO EM RONDÔNIA: UMA ANÁLISE DE ARRANJOS INSTITUCIONAIS POR CLASSIFICAÇÃO ORIENTADA A OBJETO}

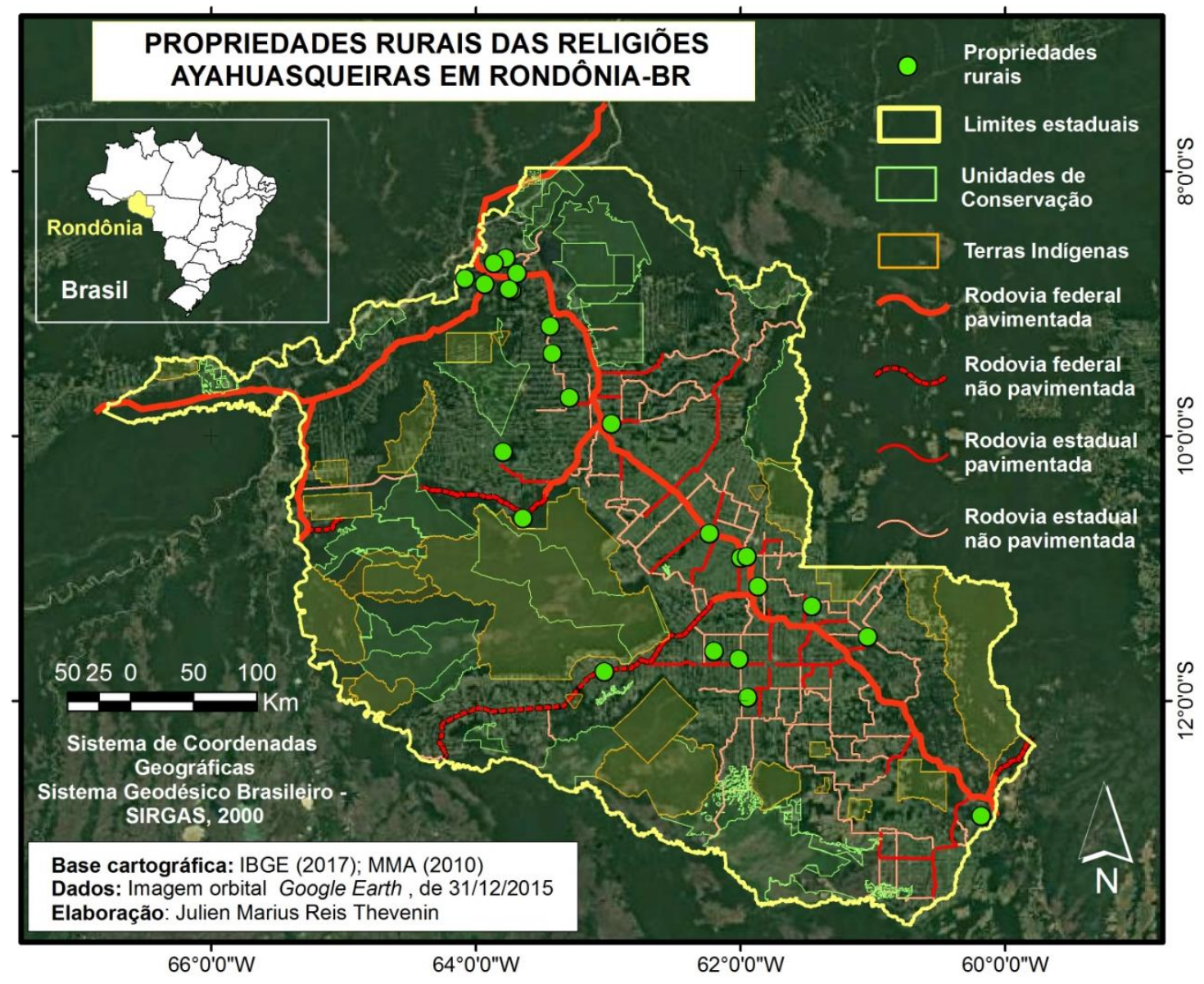

Mapa 1 - Localização das 24 propriedades rurais analisadas em território ayahuasqueiro no estado de Rondônia (Brasil).

As propriedades rurais foram delimitadas em campo, por meio do aparelho Trimble Recon GPS (Global Position System), edição XB (Tabela 1). O receptor desse GPS permite uma precisão confiável de 2 a 5 metros e foi especificamente desenvolvido para determinar posições em ambientes hostis, como debaixo de copas de árvore ou em construções (de acordo com suas especificações técnicas). 
THEVENIN, J.M.R., PIROLI, E.L.

\section{USO E COBERTURA DA TERRA NO TERRITÓRIO AYAHUASQUEIRO EM RONDÔNIA: UMA ANÁLISE DE ARRANJOS INSTITUCIONAIS POR CLASSIFICAÇÃO ORIENTADA A OBJETO}

Tabela 1 - Informações sobre as propriedades rurais da área de estudo.

\begin{tabular}{|c|c|c|c|c|}
\hline $\begin{array}{c}\text { Propriedade } \\
\text { rural/informações }\end{array}$ & Município & Área (ha) & $\begin{array}{c}\text { Data da } \\
\text { Imagem de } \\
\text { Satélite }\end{array}$ & $\begin{array}{c}\text { Ano de } \\
\text { aquisição }\end{array}$ \\
\hline 1 & Ariquemes & 8,50 & $11 / 06 / 2013$ & 1982 \\
\hline 2 & Ji-Paraná & 4,48 & $30 / 07 / 2013$ & 1985 \\
\hline 3 & Porto Velho & 12,37 & $02 / 07 / 2015$ & 1987 \\
\hline 4 & Ouro Preto do Oeste & 2,86 & $22 / 04 / 2013$ & 1987 \\
\hline 5 & Porto Velho & 20,07 & $02 / 07 / 2015$ & 1989 \\
\hline 6 & Itapuã do Oeste & 99,38 & $24 / 06 / 2010$ & 1993 \\
\hline 7 & Seringueiras & 6,15 & $24 / 06 / 2015$ & 1993 \\
\hline 8 & Presidente Médici & 2,66 & $07 / 04 / 2014$ & 1994 \\
\hline 9 & Campo Novo de Rondônia & 5,65 & $11 / 06 / 2013$ & 1996 \\
\hline 10 & Alta Floresta do Oeste & 4,22 & $19 / 08 / 2008$ & 1997 \\
\hline 11 & Candeias do Jamari & 52,33 & $02 / 07 / 2015$ & 1997 \\
\hline 12 & Candeias do Jamari & 68,19 & $24 / 06 / 2010$ & 1997 \\
\hline 13 & Ji-Paraná & 9,33 & $30 / 07 / 2013$ & 1999 \\
\hline 14 & Cacoal & 2,34 & 03/07/2015 & 2001 \\
\hline 15 & Buritis & 2,34 & 06/07/2010 & 2002 \\
\hline 16 & Candeias do Jamari & 2,19 & 03/07/2015 & 2002 \\
\hline 17 & Vilhena & 3,10 & $25 / 09 / 2013$ & 2004 \\
\hline 18 & Espigão do Oeste & 0,72 & $25 / 09 / 2013$ & 2004 \\
\hline 19 & Alto Paraíso & 1,32 & $12 / 06 / 2013$ & 2004 \\
\hline 20 & Porto Velho & 0,70 & 09/02/2016 & 2007 \\
\hline 21 & Novo Horizonte do Oeste & 8,80 & $19 / 05 / 2014$ & 2010 \\
\hline 22 & Porto Velho & 4,82 & $17 / 05 / 2015$ & 2011 \\
\hline 23 & Porto Velho & 6,31 & 09/02/2016 & 2012 \\
\hline 24 & Novo Horizonte do Oeste & 4,75 & $28 / 07 / 2010$ & 2012 \\
\hline
\end{tabular}

Fonte: Trabalho de campo, 2014.

Os pontos de coordenadas geográficas coletados foram sobrepostos às imagens de satélite no aplicativo ArcGIS 10. Após correções baseadas nas imagens e nas observações de campo, foram traçados os polígonos das propriedades. Na sequência, foi calculada a área de cada propriedade.
As informações sobre cada propriedade foram extraídas dos 24 questionários aplicados aos lideres religiosos locais e inseridas em suas tabelas de atributos (ano de aquisição, histórico de uso e ocupação, práticas de manejo agrícola e reflorestamento, perfil socioeconômico dos associados). A análise das informações obtidas 


\section{USO E COBERTURA DA TERRA NO TERRITÓRIO AYAHUASQUEIRO EM RONDÔNIA: UMA ANÁLISE DE ARRANJOS INSTITUCIONAIS POR CLASSIFICAÇÃO ORIENTADA A OBJETO}

nos questionários serviu de subsídio para reconhecer os processos associados ao uso e ocupação dos territórios analisados. Segundo Tucker e Ostrom (2009), dados coletados em lócus também oferecem uma dimensão crítica para análises multiescalares e transescalares dos fatores institucionais, políticos, socioeconômicos e ecológicos associados a mudanças em florestas.

\subsection{SENSORIAMENTO REMOTO E SISTEMAS DE INFORMAÇÕES GEOGRÁFICAS}

Por meio do aplicativo livre El-Shayal Smart Web On Line foram extraídas imagens georreferenciadas do aplicativo Google Earth (satélite Quickbird), com altitude do ponto de visão de $1,38 \mathrm{~km}$, o que resultou em uma resolução espacial de 1,42 $\mathrm{m}$ para cada uma das propriedades delimitadas. Ao extraí-las desse modo, perde-se a princípio a possibilidade de manipulação das bandas do satélite, porém em nenhuma delas foi identificada cobertura de nuvens ou outros problemas que justificassem a necessidade de análise das bandas separadamente. As mesmas foram utilizadas para - mapeamento da cobertura da terra em determinados anos no período entre 2008 a 2016. Também foram extraídas imagens históricas dos anos de 2002 a 2008, que subsidiaram a análise temporal.

No aplicativo Envi 5.0 foi realizada a classificação orientada a objetos para cada imagem recortada pelos limites das propriedades analisadas. A opção por utilizar a classificação orientada a objeto ocorreu, principalmente, devido à escala de detalhamento associado ao uso de imagens de alta resolução. A melhoria da resolução espacial proporcionada pelos avanços tecnológicos ampliou as dificuldades de aplicação dos classificadores digitais tradicionais (classificadores pixel a pixel), que foram desenvolvidos baseados em características do pixel como unidade primitiva de informações a respeito do alvo, voltados, sobretudo, às imagens de baixa resolução espacial (LUZ et al., 2010).

Segundo Chubey et al. (2006), o método orientado a objeto realiza o agrupamento de pixels com características espectrais semelhantes, analisando o tamanho, a homogeneidade espectral, a homogeneidade espacial e a forma do objeto. Essa abordagem aproxima as técnicas de processamento e extração de informações com o raciocínio humano e a capacidade de fotointerpretação, pois exige do usuário o reconhecimento da forma dos objetos, a partir de um método de delineamento denominado segmentação multirresolução (BAATZ; SHÄPE, 2000).

Diversos pesquisadores analisaram a eficiência dessa técnica para o mapeamento de uso e cobertura da terra, e obtiveram como resultado exatidão total superior aos métodos de classificação automáticos tradicionais (MITRI; GITAS, 2004; YAN et al., 2006; ROCHA, 2007).

Os parâmetros da segmentação multirresolução utilizados neste estudo foram os seguintes: o algoritmo de segmento configurado foi o de borda (Edge), com o nível de escala variando entre 40 e 50, em configurações de mesclagem; o algoritmo escolhido foi o padrão (Full Lambda Shedule), em níveis de fusão variando entre 97 a 99, sendo que os níveis foram escolhidos de acordo com o delineamento mais adequado para cada propriedade.

Além disso, os níveis médios configurados no algoritmo de segmento evitaram excesso de segmentação e/ou ausência das mesmas, na busca de atingir limites equivalentes aos limites das classes de cobertura da terra definidas a seguir; já as configurações de mesclagem buscaram fundir o máximo de pequenos segmentos dentro de áreas maiores, onde o excesso de segmentação pudesse ser um problema; por fim, o tamanho da textura Kernel foi para todos igual a 15 pois, embora as áreas fossem pequenas, não havia uma grande variância de textura entre as classes.

Keramitsoglou et al. (2005) considera que o algoritmo KRC (Kernel based reclassification) é construído pela combinação de informações espectrais e texturais na vizinhança de cada pixel, mais especificamente dentro da célula quadrada de Kernel (a mesma utilizada nos filtros digitais) onde o arranjo espacial e frequência dos pixels é que determina a 


\section{USO E COBERTURA DA TERRA NO TERRITÓRIO AYAHUASQUEIRO EM RONDÔNIA: UMA ANÁLISE DE ARRANJOS INSTITUCIONAIS POR CLASSIFICAÇÃO ORIENTADA A OBJETO}

rerotulação dos mesmos a uma determinada classe temática. Esses autores, ao compararem o tamanho da célula quadrada de Kernel de 9X9 e o de $15 \times 15$ pixels, mostraram que a maior célula determina uma maior homogeneização das classes, porém oculta algumas feições importantes que puderam ser detectadas quando da utilização da célula menor.

Após a segmentação, as classes foram definidas no painel de regras de classificação, onde foi selecionado o atributo pertinente a cada classe de acordo com as características específicas dessas áreas, sendo as mesmas: sucessão secundária (inicial, intermediária ou avançada), agricultura/pastagem, área sem vegetação (solo exposto ou área construída) e massa d'água.

As áreas de vegetação em diferentes estágios sucessionais foram definidas de acordo com Mausel et al. (1993), considerando três níveis: estágio inicial (SS1), no qual ocorre vegetação graminoide dispersa entre vegetação de porte arbóreo em crescimento; estágio intermediário (SS2), caracterizado pela presença de árvores entre 8 e $12 \mathrm{~m}$ de altura, com uma estratificação vertical relativamente evidente; e, finalmente, o estágio avançado (SS3), no qual o dossel apresenta uma estratificação vertical mais evidente do que em SS2 e com árvores normalmente excedendo $20 \mathrm{~m}$ de altura.

Devido ao grau de intervenção antrópica nas áreas estudadas, não foi considerada uma classe específica para floresta primária, pois na maioria dos casos as florestas sofreram corte seletivo (antes da aquisição da propriedade pelas instituições analisadas) ou efeito de borda, principalmente por força do predomínio de pastagens no entorno das áreas de estudo. Já o plantio das espécies Banisteriopsis caapi e Psychotria viridis ocorre em áreas específicas das propriedades, sob vegetação em estágio avançado ou intermediário de sucessão.

Após a classificação orientada a objeto, foi realizada uma edição vetorial manualmente no ArcGIS 10 com o objetivo de corrigir os erros da mesma em todas as propriedades. Segundo Pratt (2007), uma análise realizada pelos olhos humanos continua sendo a fonte mais robusta e experiente para avaliação de técnicas de segmentação. As imagens classificadas foram transformadas em mapas de cobertura da terra, em escala compatível ao nível de detalhamento das imagens (1:3.000).

\section{RESULTADOS E DISCUSSÃO \\ 3.1. DAS DIMENSÕES TERRITORIAIS À FISIONOMIA DA COBERTURA VEGETAL}

A soma das áreas do território religioso analisado em Rondônia, constituído pelas 24 propriedades rurais, foi de 333,58 hectares (ha). Essas propriedades têm como função principal o cultivo de $B$. caapi e $P$. viridis em sistemas agroflorestais, exceto cinco, que além dessa destinação, são também sedes locais das religiões.

A primeira propriedade rural destinada ao plantio das plantas ritualísticas em Rondônia foi adquirida em 1982 pela UDV, no município de Ariquemes. Tal iniciativa fora realizada 21 anos após a criação desse Centro (1961), embora já houvesse a prática desse cultivo em áreas urbanas de Porto Velho, Ji-Paraná, Jaru e Ariquemes, tanto pela CEBUDV quanto também pelo Centro Eclético de Correntes da Luz Universal (CECLU).

A expansão dessas áreas cultivadas foi exponencial, principalmente a partir de 1990, década em que foram adquiridas 33,33\% das propriedades, o maior número até então. $\mathrm{Na}$ década de 2000, esse crescimento se manteve em $29,16 \%$ do total, com a aquisição de mais 07 propriedades rurais. Enquanto que só nos três primeiros anos da década de 2010, foram adquiridas 04 propriedades rurais $(16,66 \%)$, o que mostra uma tendência à expansão dessas áreas concomitante com a expansão dessas religiões.

De modo geral, os resultados do mapeamento da cobertura da terra mostraram que aproximadamente $81,4 \%(271,60 \mathrm{ha})$ da somatória das áreas das 24 propriedades estão cobertas por vegetação nativa, de porte arbóreo dominante, o que equivale ao estágio avançado de sucessão da vegetação. Por outro lado, se 


\section{USO E COBERTURA DA TERRA NO TERRITÓRIO AYAHUASQUEIRO EM RONDÔNIA: UMA ANÁLISE DE ARRANJOS INSTITUCIONAIS POR CLASSIFICAÇÃO ORIENTADA A OBJETO}

considerarmos os estágios sucessionais intermediário e avançado, esse percentual sobe para aproximadamente $92,5 \%(308,64$ ha) de áreas rurais cobertas por vegetação nativa nesses territórios.

Vale destacar que o cultivo das espécies $B$. caapi e $P$. viridis é realizado na área de estudo em porções restritas das propriedades e, por vezes, bastante dispersas normalmente sob a cobertura de porte arbórea, o que dificultou um mapeamento preciso do mesmo. Três sistemas de manejo dessas espécies foram observados, quanto às técnicas de implantação: a partir do raleamento da vegetação, com corte de algumas árvores de dossel e raso do sub-bosque; a partir da restauração florestal em áreas em estágio inicial de regeneração da vegetação; e sem corte da vegetação em áreas com vegetação em estágio intermediário ou avançado de regeneração. Além disso, adensamentos florestais com espécies arbóreas endêmicas pioneiras, secundárias e clímax são comumente realizados nesses três sistemas.

Ainda considerando-se a área total de propriedades, obteve-se que 6,52 ha $(2 \%)$ foram classificados como área de pastagem ou de agricultura convencional. Por motivo desses usos serem anteriores à aquisição das propriedades por esses grupos religiosos, a maior parte não tem sido mais utilizada como pasto ou para agricultura convencional e a tendência delas, assim como dos 13,60 ha $(4,1 \%)$ de cobertura herbáceo arbustiva, é a regeneração e a recomposição da vegetação nativa para cultivo de $B$. caapi e $P$. viridis. As áreas sem vegetação que somaram 4,46 ha $(1,3 \%)$ são referentes a áreas de ocupação consolidadas das propriedades e incluem, na maioria das vezes, edificações e estradas de acesso (Figura 1).

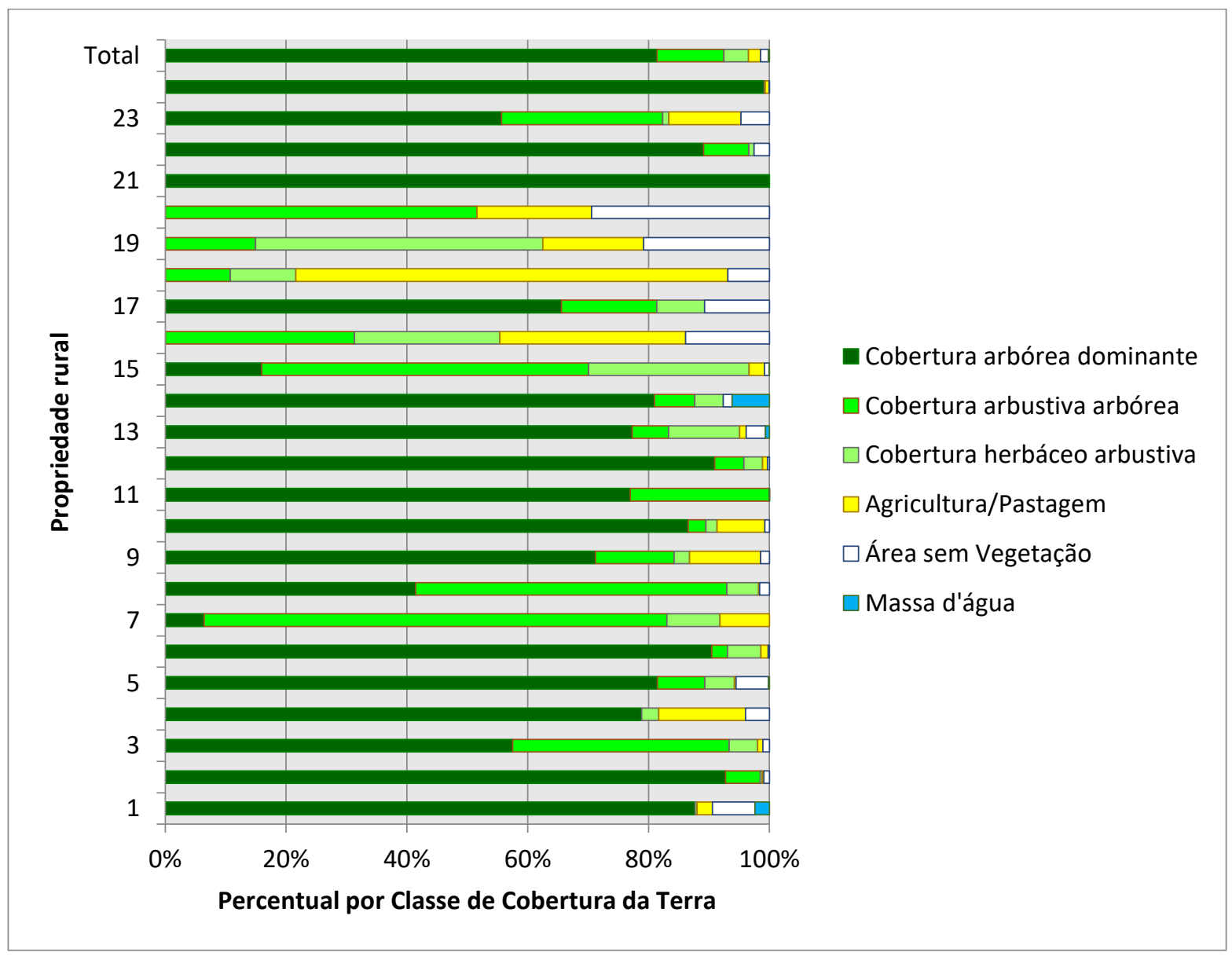

Figura 1 - Distribuição percentual das classes de cobertura da terra por propriedade rural e área total. 


\section{USO E COBERTURA DA TERRA NO TERRITÓRIO AYAHUASQUEIRO EM RONDÔNIA: UMA ANÁLISE DE ARRANJOS INSTITUCIONAIS POR CLASSIFICAÇÃO ORIENTADA A OBJETO}

As propriedades 16, 18, 19 e 20, que apresentaram os menores percentuais de cobertura vegetal (menores que 65\%), possuem algumas características em comum. Primeiramente, são as quatro menores em extensão total, com 2,19,0,72, 1,32 e 0,70 ha respectivamente, sendo três delas sedes locais das religiões analisadas e a outra, a 18, uma futura sede. Além disso, localizam-se próximo a áreas urbanas em paisagens dominadas por pastagens e sofrem com intensos efeitos de borda.

Propriedades como a 3, 7, 8, 15 e 23, embora possuam dimensões um pouco maiores (12,37, 6,15, 2,66, 2,34 e 6,31 ha, respectivamente) e cobertura vegetal acima dos $80 \%$, detêm percentuais de cobertura arbórea dominante inferiores aos $60 \%$, destacando-se por possuírem mais de $20 \%$ de cobertura arbustiva arbórea. O que pode estar associado aos efeitos de borda que sofrem, já que estas também aparecem nas imagens de satélite como fragmentos isolados em uma paisagem antropizada (exceto a propriedade 23, que se insere em um fragmento florestal maior).

O aumento das bordas da floresta gerado por sua fragmentação incide diretamente no aumento das taxas de mortalidade de animais e plantas, conforme Kapos et al. (1997), ocasionado pelas mudanças repentinas e abruptas na temperatura do ar e na umidade do ar e do solo, mudanças que chegam a ultrapassar as tolerâncias fisiológicas de algumas árvores. Além disso, a área desmatada em torno dos fragmentos contribui para o aumento na velocidade do vento sobre as bordas, o que ocasiona a derrubada de muitas árvores (FERREIRA; LAURANCE, 1997)

Dependendo do tipo de efeito de borda, a distância de sua penetração pode variar entre 10 a 400m na Amazônia Central (LAURENCE et al. 2002). O que faz com que os fragmentos menores sejam proporcionalmente mais afetados do que os grandes (MURCIA, 1995).

Tais afirmações se confirmam também ao se observar que nas propriedades $1,2,5,6$,
$10,12,14,21,22$ e 24, as quais possuem taxas de cobertura arbórea dominante acima dos $80 \%$, apenas a 2 e a 24 não estão inseridas em fragmentos florestais maiores que seus limites territoriais. Essa análise, com base na estrutura da paisagem de entorno, só é possibilitada por motivo das práticas de gestão e manejo desses territórios serem de baixo impacto sobre a vegetação nativa, restringindo-se a raleamentos pontuais do sub-bosque, adensamentos e reflorestamentos.

\subsection{O CUMPRIMENTO DA RESERVA LEGAL E A RECUPERAÇÃO DE ÁREAS DEGRADADAS}

Para análise das propriedades sob a ótica da legislação ambiental vigente, inicialmente, deve-se considerar que todas possuem menos de 02 módulos fiscais e que 0 módulo fiscal no estado de Rondônia é de 60 hectares, como nos mostra Landau et al. (2012). Dessa forma, as propriedades estudadas se encontram amparadas pelo artigo 67 da Lei n.으 12.651, de 25 de maio de 2012, que instituiu:

\begin{abstract}
Art. 67. Nos imóveis rurais que detinham, em 22 de julho de 2008, área de até 4 (quatro) módulos fiscais e que possuam remanescente de vegetação nativa em percentuais inferiores ao previsto no art. 12, a Reserva Legal será constituída com a área ocupada com a vegetação nativa existente em 22 de julho de 2008, vedadas novas conversões para uso alternativo do solo (BRASIL, 2012a).
\end{abstract}

Vale ressaltar que o Art. 12 da Lei n.ㅇ $12.651 / 2012$ institui que todo imóvel rural na Amazônia Legal deve manter área com cobertura de vegetação nativa, a título de Reserva Legal, sem prejuízo da aplicação das normas sobre as Áreas de Preservação Permanente - APP, com um percentual mínimo em relação à sua área total de $80 \%$, excetuados os proprietários ou possuidores de imóveis rurais que realizaram supressão de vegetação nativa, respeitando os percentuais de 


\section{USO E COBERTURA DA TERRA NO TERRITÓRIO AYAHUASQUEIRO EM RONDÔNIA: UMA ANÁLISE DE ARRANJOS INSTITUCIONAIS POR CLASSIFICAÇÃO ORIENTADA A OBJETO}

Reserva Legal previstos pela legislação em vigor à época.

A Lei supracitada permite, conforme foi estabelecido pela Lei complementar n.o 312, de 06 de maio de 2005, que dispõe sobre Zoneamento Ecológico-Econômico do Estado de Rondônia - ZEE, a redução, exclusivamente para fins de regularização, mediante recomposição, regeneração ou compensação da Reserva Legal de imóveis com área rural consolidada, situados em área de floresta localizada na Amazônia Legal, para até $50 \%$ da propriedade, excluídas as áreas prioritárias para conservação da biodiversidade e dos recursos hídricos e os corredores ecológicos (RONDÔNIA, 2005).

A lei ambiental entende por vegetação nativa a floresta nativa e suas formações sucessoras (inicial, intermediária, avançada) e não define a vegetação primária e secundária, e suas formações sucessoras no bioma Amazônico, conforme algumas resoluções do Conselho Nacional do Meio Ambiente - CONAMA têm feito para a Mata Atlântica.

Independente do sistema implantado e da área abrangida, essas propriedades estão respaldadas na Lei $n$.o 12.651 , tendo em vista que a implantação desses plantios ocorreu em data anterior a 22 de julho de 2008, com exceção das propriedades 21, 22, 23 e 24, que foram adquiridas após essa data.

A partir do trabalho de campo, imagens de satélite e da classificação da cobertura da terra, verificou-se que as propriedades 21,22 e 24 implantaram os sistemas de plantio por raleamento e/ou sem corte da vegetação, sob cobertura arbustiva arbórea e arbórea dominante, em pequenas áreas das propriedades excedentes aos $80 \%$ destinados à Reserva Legal. No caso exclusivo da propriedade 23 , o plantio de $B$. caapi e $P$. viridis foi realizado dentro da faixa de $80 \%$ de vegetação nativa destinada à Reserva Legal, coberta por vegetação de porte arbustiva arbórea, porém sem supressão da vegetação. Tal uso encontra-se respaldado no Art. 21, da Lei n.o 12.651/2012, que torna livre, em áreas de Reserva Legal, a coleta de produtos florestais não madeireiros, tais como frutos, cipós, folhas e sementes, posto que essas plantas são endêmicas deste bioma.

No conjunto das propriedades, apenas as 16, 18, 19 e 20 apresentaram áreas de vegetação nativa menor que os $80 \%$. A partir da análise de imagens orbitais históricas extraídas do aplicativo Google Earth, em alta resolução, referente às datas de 20/07/2008, 23/09/2003, $17 / 07 / 2002$ e 17/05/2003 respectivamente, foi possível confirmar que a supressão vegetal dessas propriedades foi anterior a 22 de julho de 2008 (mostradas nos mapas 2, 3, 4, 5), o que os isenta de responsabilidade legal quanto às áreas suprimidas. 


\section{USO E COBERTURA DA TERRA NO TERRITÓRIO AYAHUASQUEIRO EM RONDÔNIA: UMA ANÁLISE DE ARRANJOS INSTITUCIONAIS POR CLASSIFICAÇÃO ORIENTADA A OBJETO}

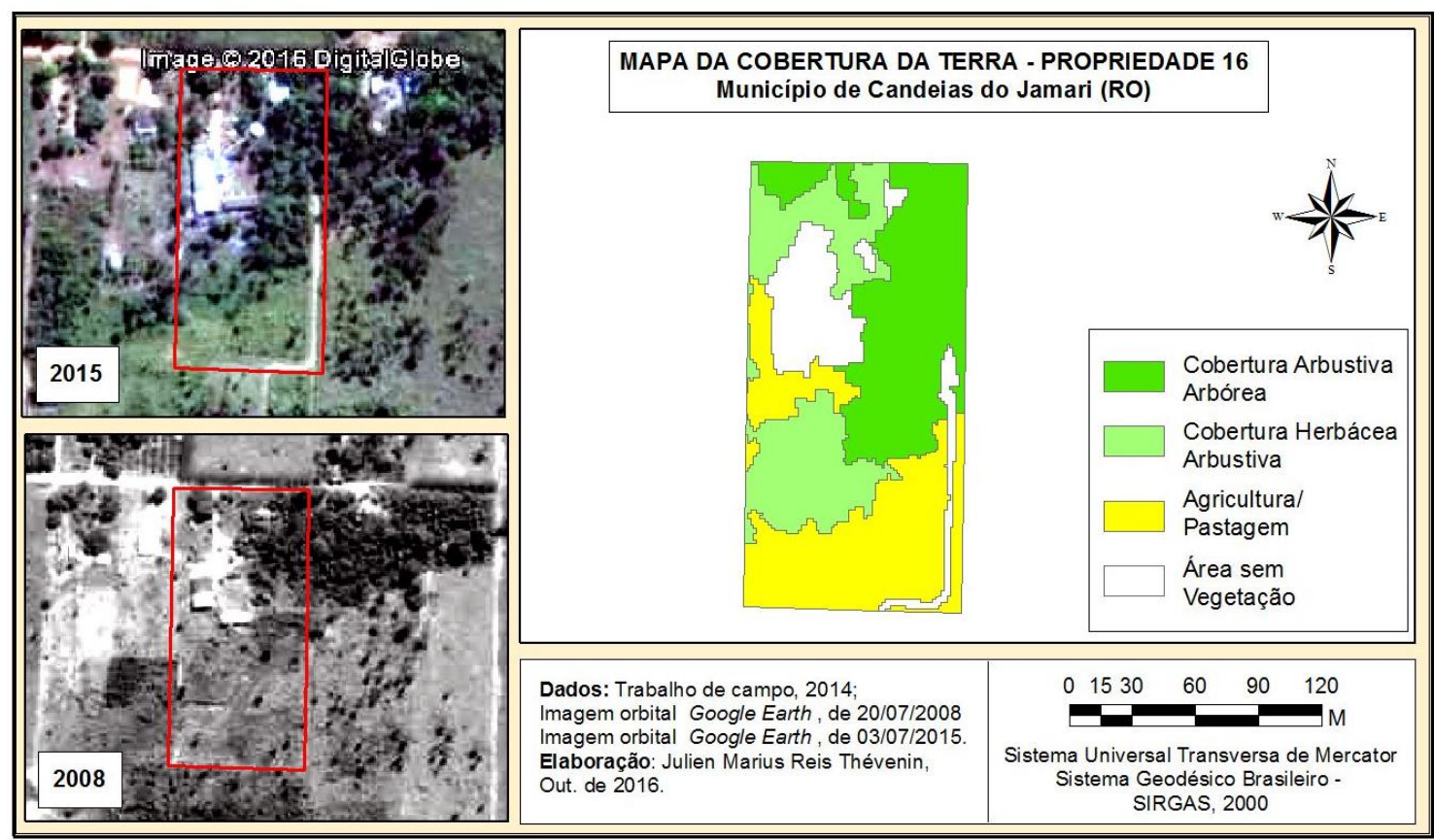

Mapa 2 - Cobertura da terra na propriedade rural 16, no ano de 2015, com série de imagens orbitais históricas, no município de Candeias do Jamari-RO9.

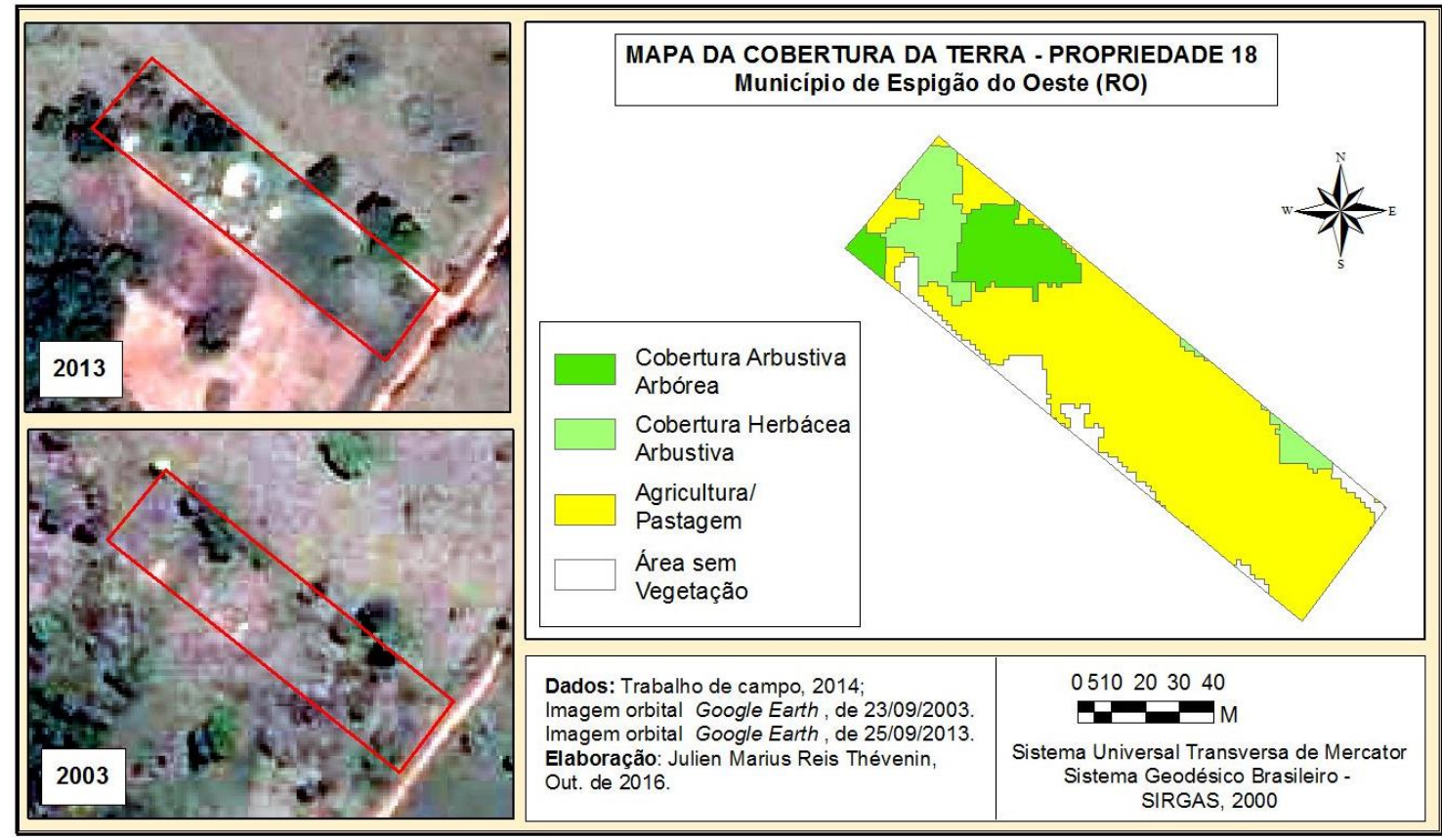

Mapa 3 - Cobertura da terra na propriedade rural 18, no ano de 2013, com série de imagens orbitais históricas, no município de Espigão do Oeste-RO.

\footnotetext{
${ }^{9}$.As coordenadas geográficas e os nomes das propriedades foram omitidos para preservar o direito à intimidade e privacidade
} das instituições, a pedido das mesmas. 


\section{USO E COBERTURA DA TERRA NO TERRITÓRIO AYAHUASQUEIRO EM RONDÔNIA: UMA ANÁLISE DE ARRANJOS INSTITUCIONAIS POR CLASSIFICAÇÃO ORIENTADA A OBJETO}

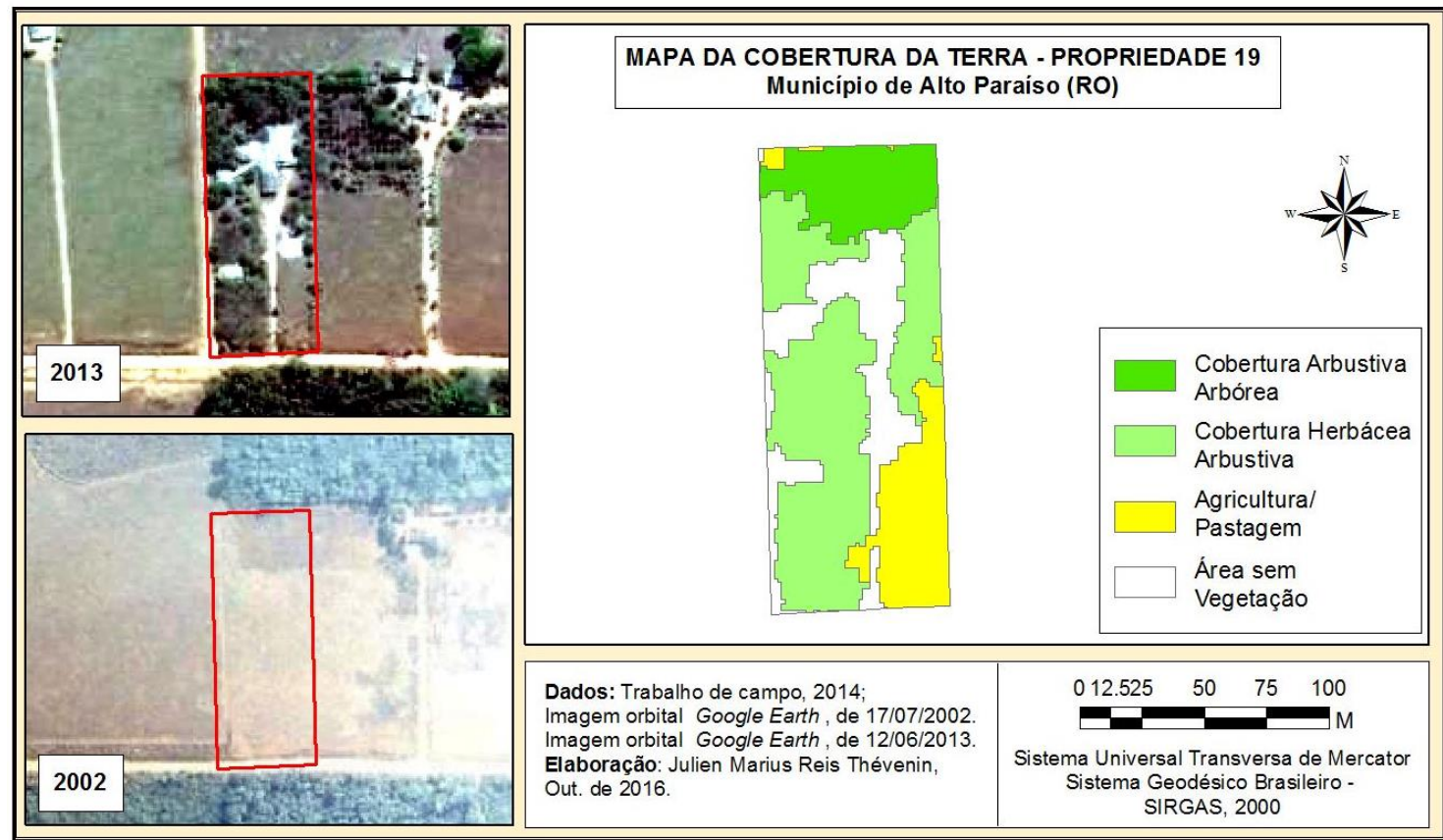

Mapa 4 - Cobertura da terra na propriedade rural 19, no ano de 2013, com série de imagens orbitais históricas, no município de Alto Paraíso-RO.

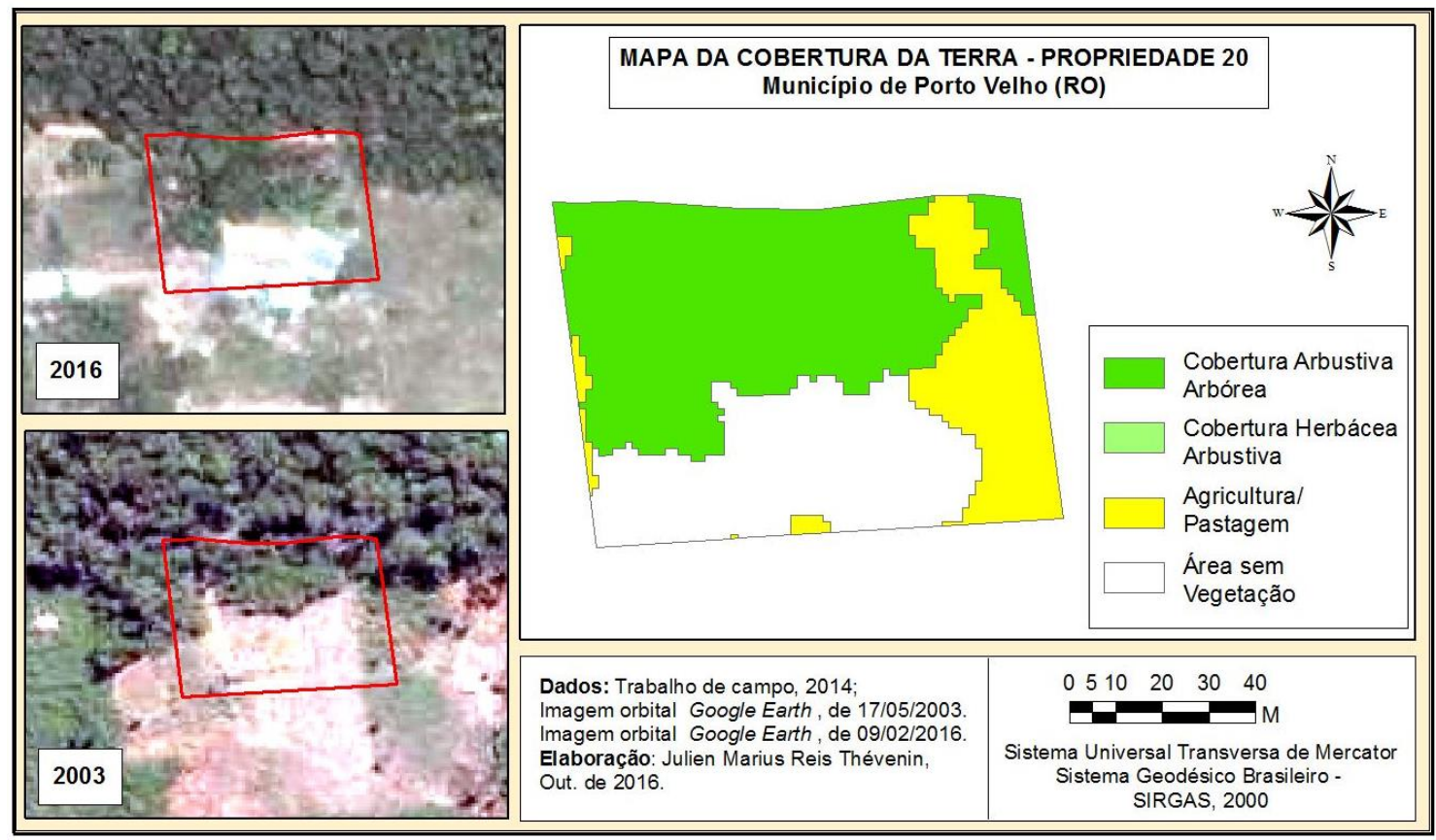

Mapa 5 - Cobertura da terra na propriedade rural 20, no ano de 2016, com série de imagens orbitais históricas, município de Porto Velho-RO.

Nas propriedades 18,19 e 20, as imagens possibilitaram também confirmar que essa supressão vegetal foi realizada em período anterior à aquisição dessas propriedades pelas religiões ayahuasqueiras.
Na propriedade 16, na qual o período da imagem histórica (2008) não possibilitou sua visualização anterior à sua aquisição pelas comunidades religiosas (2002), foi informado em questionário que seu uso e cobertura eram compostos basicamente por plantio de 


\section{USO E COBERTURA DA TERRA NO TERRITÓRIO AYAHUASQUEIRO EM RONDÔNIA: UMA ANÁLISE DE ARRANJOS INSTITUCIONAIS POR CLASSIFICAÇÃO ORIENTADA A OBJETO}

mandioca, algumas árvores frutíferas e esparsos remanescentes de vegetação nativa, mesmo antes de sua aquisição que, posteriormente, foram queimados por fogo alastrado da queima de um lixão em área próxima à propriedade. Contudo, nessa propriedade, assim como nas outras três, foi possível observar com base nos questionários e na série de imagens orbitais a recuperação de áreas degradadas, proporcionada, principalmente, por restauração florestal (com o plantio de espécies arbóreas nativas) e implantação de SAFs para cultivo das plantas ritualísticas.

Os resultados de cobertura por vegetação nativa, nessas propriedades, são consideravelmente altos se levarmos em consideração o cumprimento histórico da Reserva Legal no Brasil, assim como o desmatamento nas regiões onde essas propriedades se concentram. Segundo Oliveira e Bacha (2003), no Brasil, desde a década de 1970, tem sido comum o desrespeito ao cumprimento da Reserva Legal, sendo o percentual dos imóveis que declaram tê-la abaixo dos $10 \%$, bastante altos, e mesmo os que a cumprem não mantêm a área mínima definida por lei.

\subsection{ENTRE OCUPAÇÕES CONSOLIDADAS E MATAS CILIARES CONSERVADAS}

Quanto às APP nas propriedades, não foram identificados, em pesquisa de campo, topos de morros, montes, montanhas e serras, nem áreas de alta altitude ou alta declividade, tendo em vista a predominância de um relevo pouco dissecado nas áreas visitadas, dividido basicamente, de acordo com a classificação de Ross (2006), entre a "Depressão marginal sul amazônica" e o "Planalto e chapadas da bacia dos Parecis".

As únicas áreas passíveis de preservação permanente foram faixas marginais de cursos d'água naturais, nas quais apenas as propriedades 1 e 5 possuem área consolidada sem vegetação nativa (edificações e estradas de acesso da propriedade) - anterior à 22 de Julho de 2008, como pode ser confirmado nas imagens orbitais históricas - para fins de ocupação, com dimensões de 0,80 ha e 0,84 ha, respectivamente (Mapas 6 e 7). A área consolidada da propriedade 1 está respaldada na Lei n.o 12.727, de 2012, já que se encontra afastada a mais de 5 metros da faixa marginal do curso d'água, enquanto que a propriedade 5 precisará fazer a recomposição de 5 metros.

Art. 61-A. Para os imóveis rurais com área de até 1 (um) módulo fiscal que possuam áreas consolidadas em Áreas de Preservação Permanente ao longo de cursos d'água naturais, será obrigatória a recomposição das respectivas faixas marginais em 5 (cinco) metros, contados da borda da calha do leito regular, independente da largura do curso d'água (BRASIL, 2012b). 


\section{USO E COBERTURA DA TERRA NO TERRITÓRIO AYAHUASQUEIRO EM RONDÔNIA: UMA ANÁLISE DE ARRANJOS INSTITUCIONAIS POR CLASSIFICAÇÃO ORIENTADA A OBJETO}

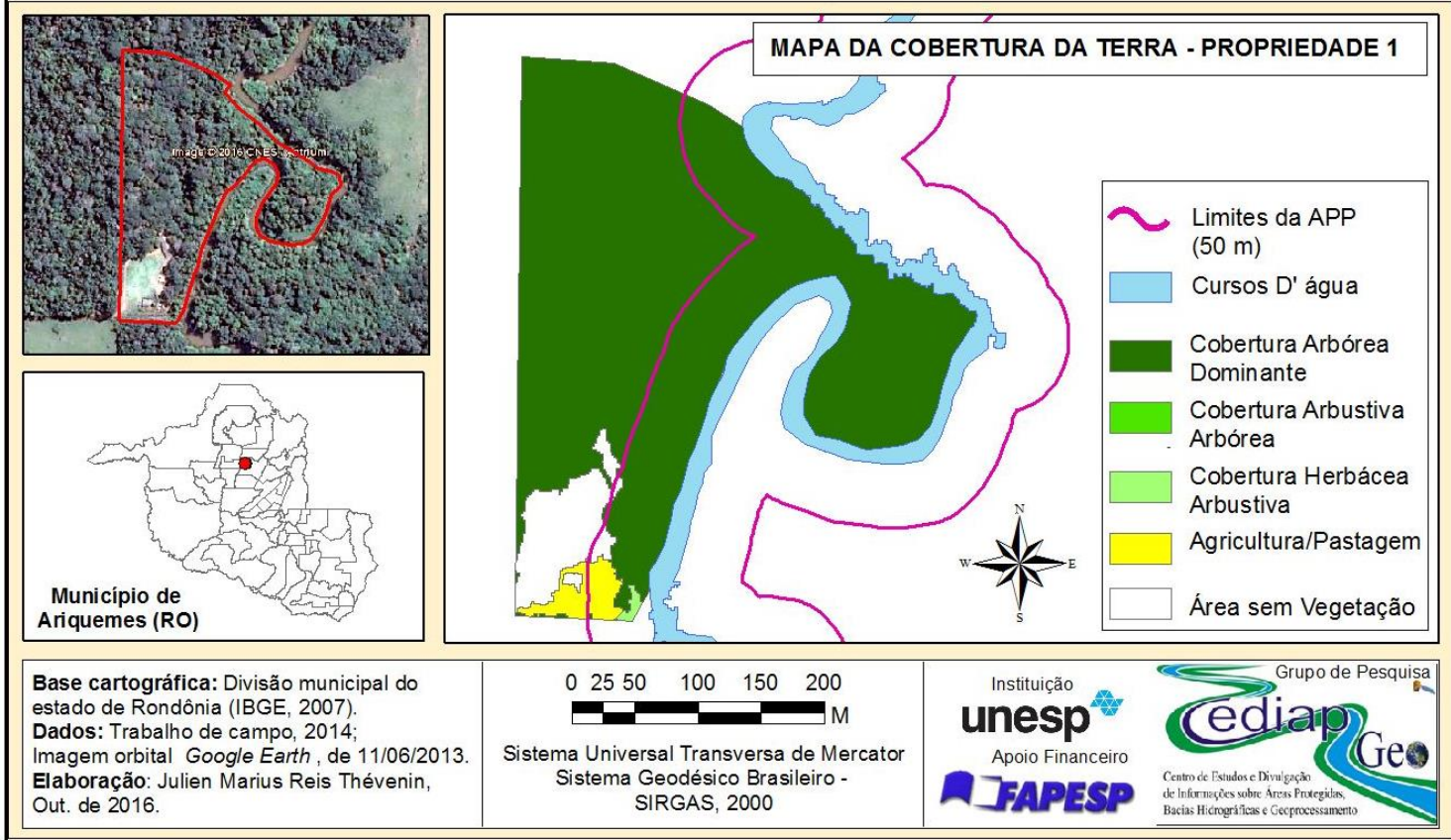

Mapa 6 - Cobertura da terra na propriedade rural 1, no município de Ariquemes-RO, no ano de 2013.

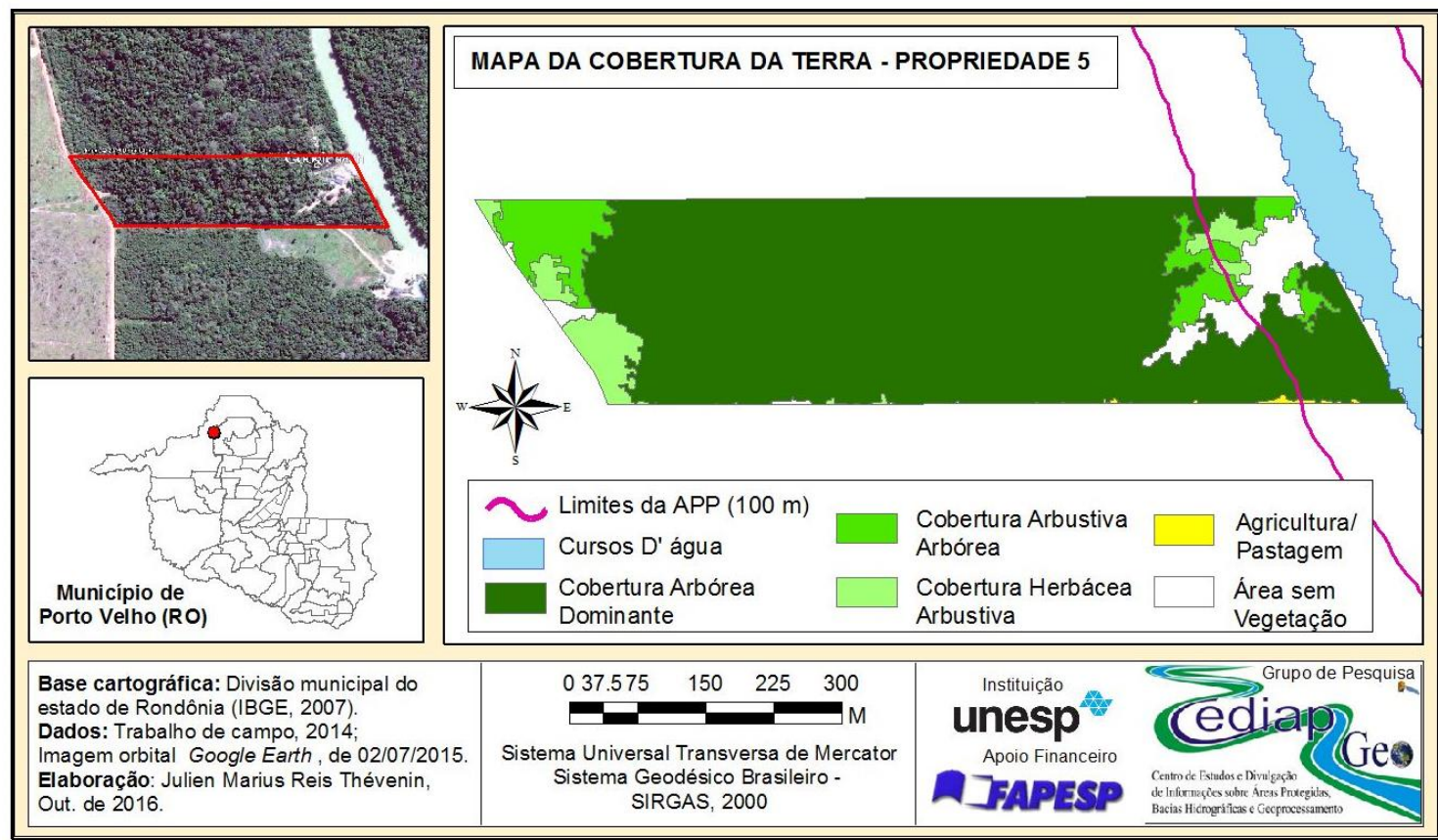

Mapa 7 - Cobertura da terra na propriedade rural 5, no município de Porto Velho-RO, no ano de 2015.

Os demais usos em APP foram consolidados também em período anterior à data de 22 de julho de 2008 nas propriedades 1, 3, 5 e 11 , sendo os mesmos relacionados ao plantio das espécies $B$. caapi e $P$. viridis, sob vegetação nativa em estágio intermediário e avançado de sucessão (Mapas 6, 8, 7 e 9, respectivamente). Segundo o
Art. 61-A da mesma Lei, "nas Áreas de Preservação Permanente é autorizada, exclusivamente, a continuidade das atividades agrossilvipastoris, de ecoturismo e de turismo rural em áreas rurais consolidadas até 22 de julho de 2008". Já nas propriedades 9 e 13 não foram identificados qualquer tipo de uso ou ocupação 


\section{USO E COBERTURA DA TERRA NO TERRITÓRIO AYAHUASQUEIRO EM RONDÔNIA: UMA ANÁLISE DE ARRANJOS INSTITUCIONAIS POR CLASSIFICAÇÃO ORIENTADA A OBJETO}

em área de APP, exceto por resquícios de usos anteriores por pastagem na propriedade 9, mas na qual a vegetação nativa já se encontra em regeneração (Mapas 10 e 11).

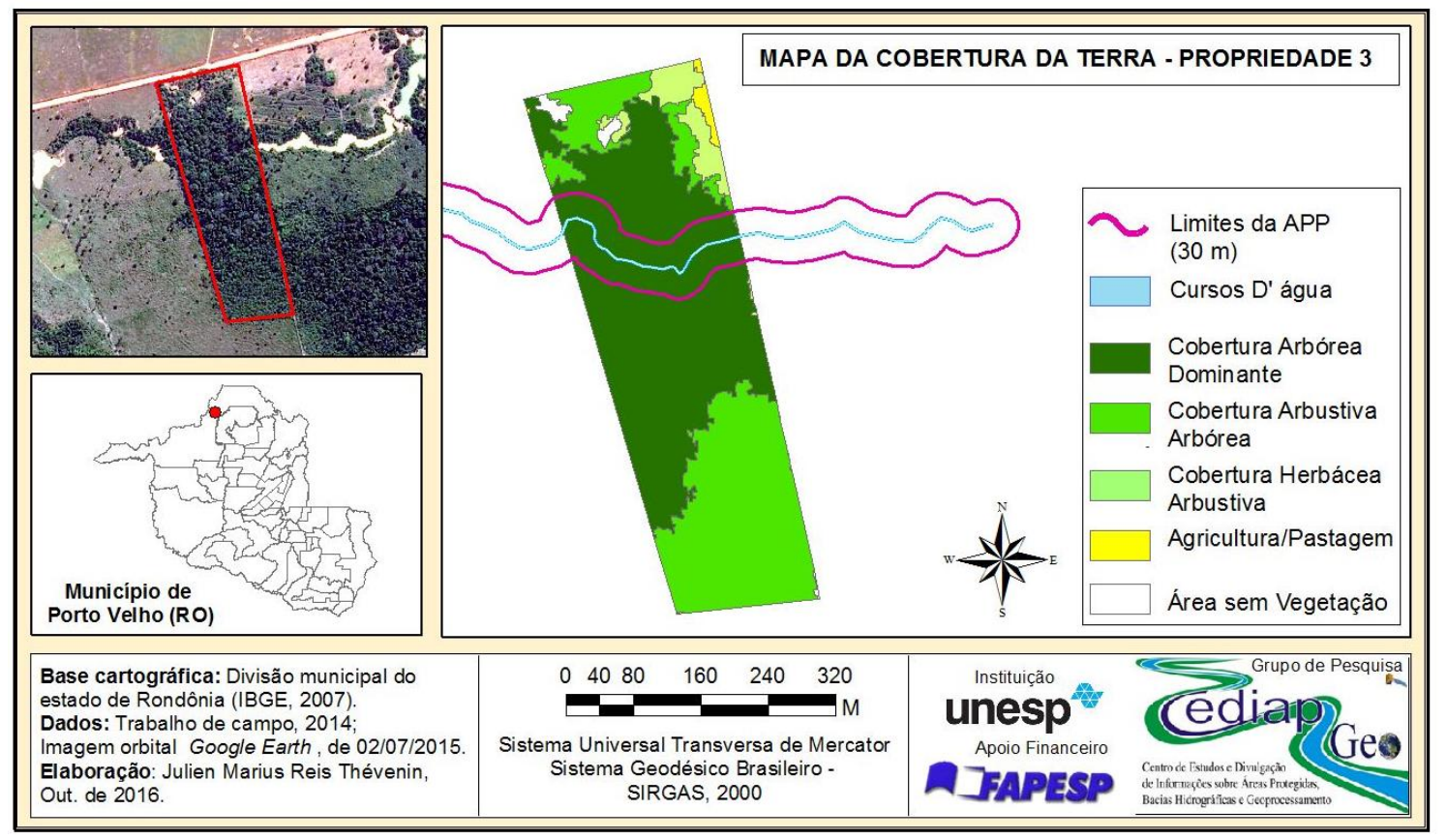

Mapa 8 - Cobertura da terra na propriedade rural 3, no município de Porto Velho-RO, no ano de 2015.

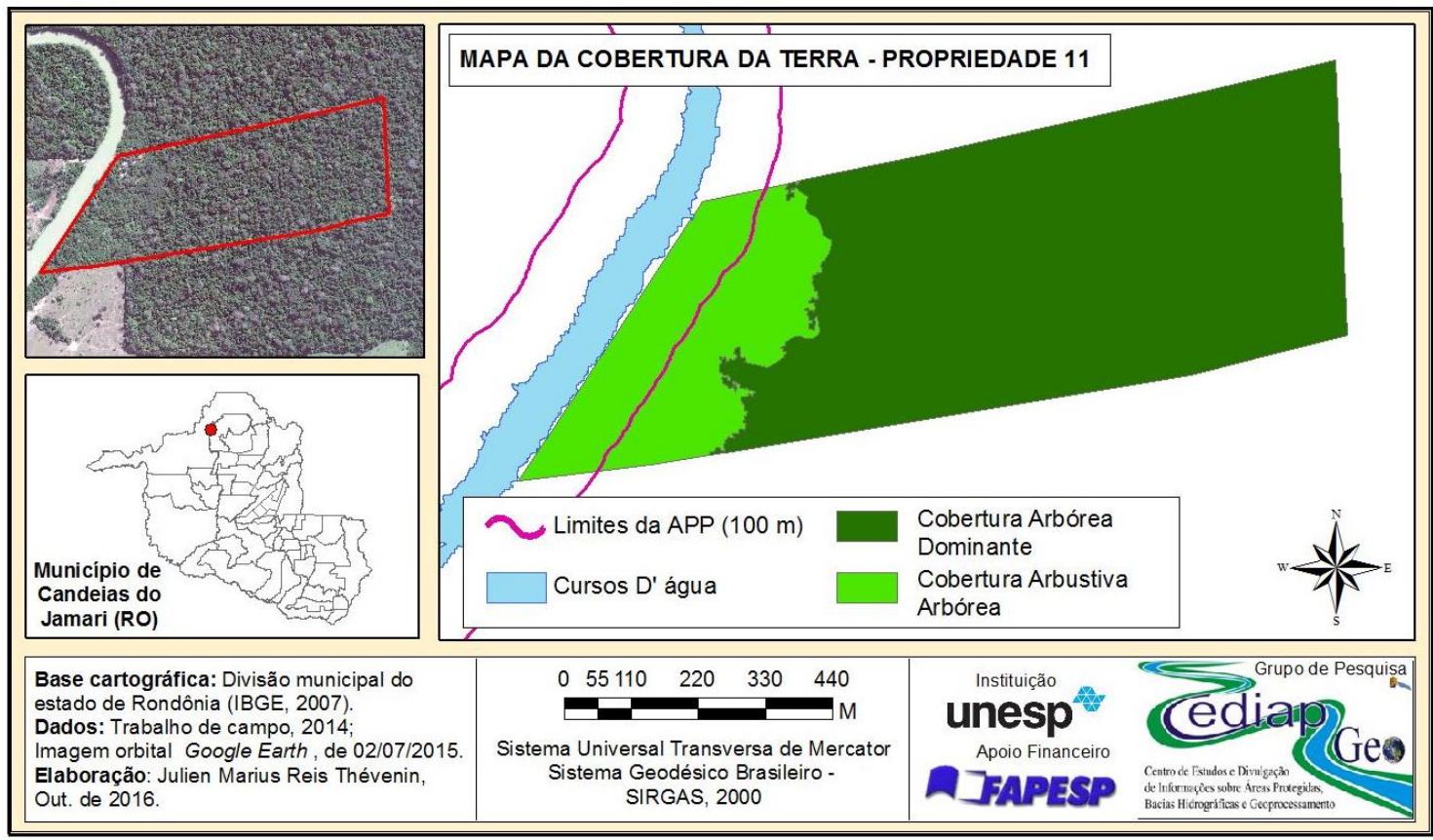

Mapa 9 - Cobertura da terra na propriedade rural 11, no município de Candeias do Jamari-RO, no ano de 2015. 


\section{USO E COBERTURA DA TERRA NO TERRITÓRIO AYAHUASQUEIRO EM RONDÔNIA: UMA ANÁLISE DE ARRANJOS INSTITUCIONAIS POR CLASSIFICAÇÃO ORIENTADA A OBJETO}

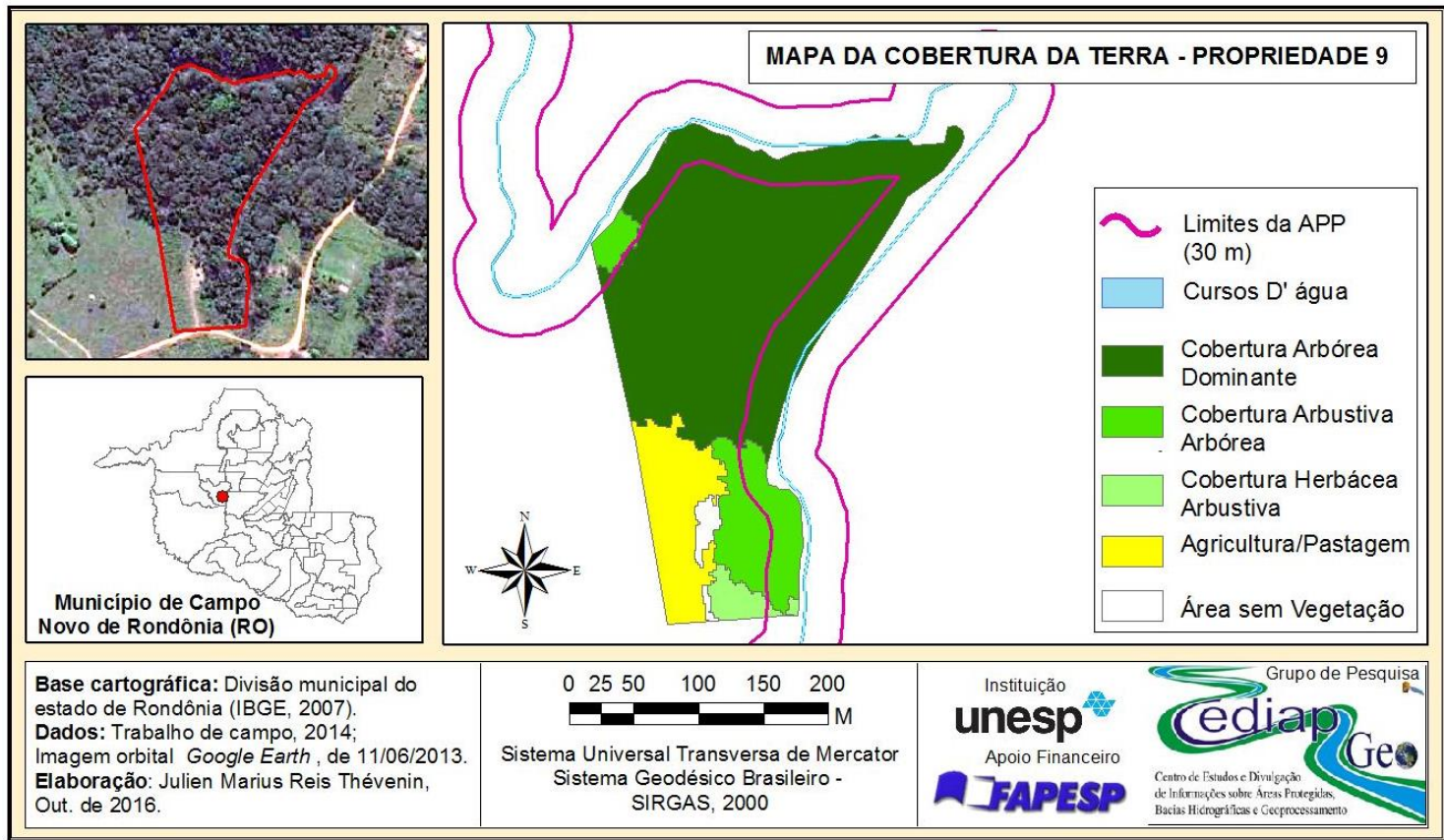

Mapa 10 - Cobertura da terra na propriedade rural 9, no município de Campo Novo de Rondônia-RO, no ano de 2013.

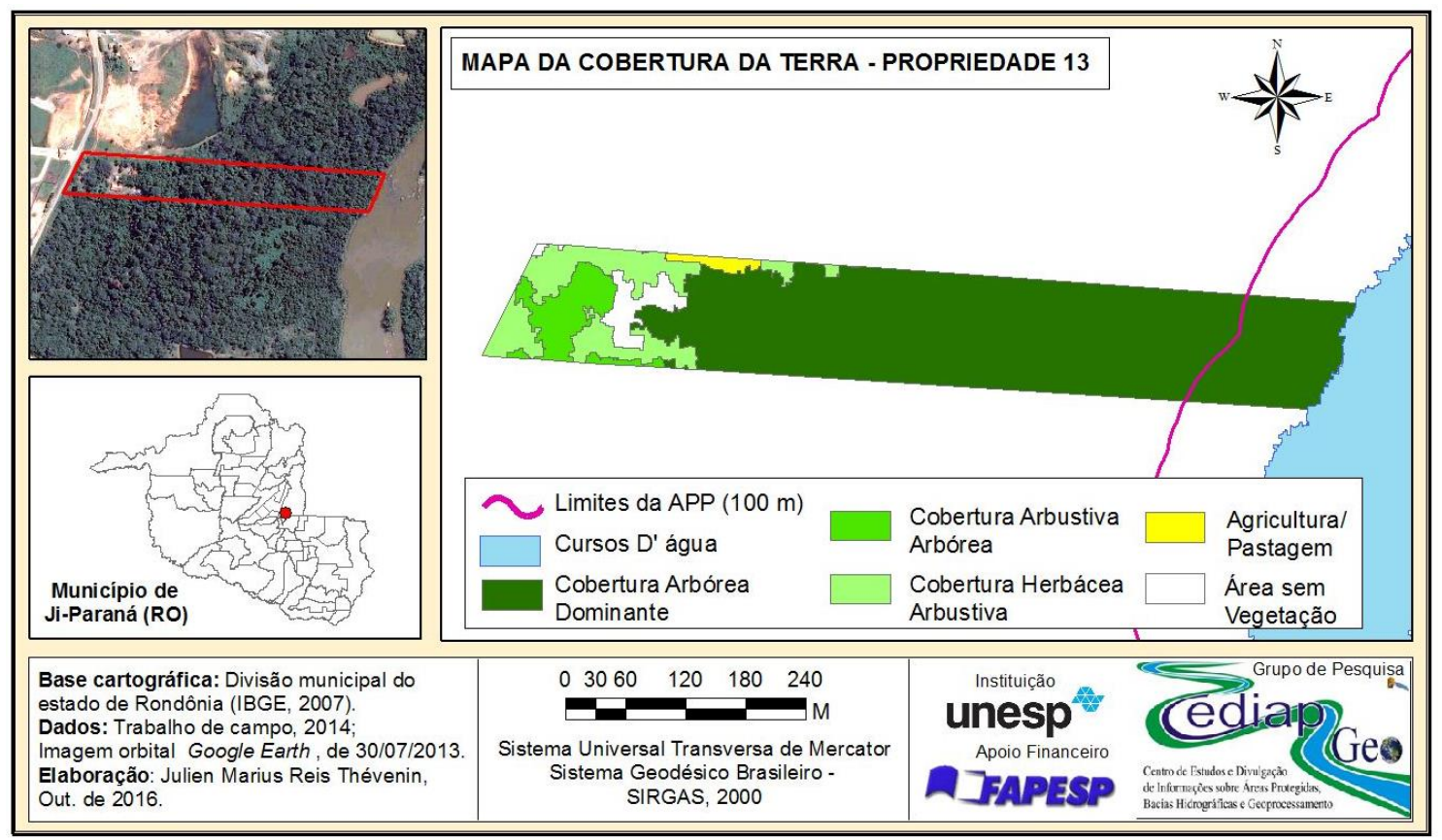

Mapa 11 - Cobertura da terra na propriedade rural 13, no município de Ji-Paraná-RO, no ano de 2013.

De modo geral, a análise da cobertura da terra das propriedades rurais dos territórios ayahuasqueiros confirmou que as normas formais, tanto as relacionadas às Reservas Legais quanto às APP, encontram-se em uso. Em alguns casos específicos - como o das propriedades 1,3 , $5,11,16,18,19$ e 20 - não há irregularidade somente por força das alterações trazidas ao Código Florestal pela Lei n. 12.651, de 25 de maio de 2012. No entanto, é notável que essas áreas de ocupação consolidadas, anteriores a 22 de julho de 2008, anistiadas por essa Lei, na maioria das vezes, tiveram a supressão da 


\section{USO E COBERTURA DA TERRA NO TERRITÓRIO AYAHUASQUEIRO EM RONDÔNIA: UMA ANÁLISE DE ARRANJOS INSTITUCIONAIS POR CLASSIFICAÇÃO ORIENTADA A OBJETO}

vegetação nativa em período anterior à aquisição das mesmas pelas religiões ayahuasqueiras.

Foi visto que as áreas de cultivo de $B$. caapi e $P$. viridis existentes se adéquam a lei sem prejuízos, no entanto para as novas áreas de plantio que, porventura, venham a ser implantadas nessas áreas protegidas recomendase que seja observado o sistema de plantio mais adequado à legislação vigente.

Dentre as propriedades destacam-se a 2 , $6,10,11,12,13,14,21,22$ e 24 que apresentam condições mais favoráveis para receber benefícios como o de servidão ambiental, Cota de Reserva Ambiental - CRA e outros instrumentos congêneres previstos em lei, pois estão situadas na Amazônia Legal, possuem índice de Reserva Legal maior que $50 \%$ de cobertura florestal e não realizaram a supressão da vegetação nos percentuais previstos pela legislação em vigor à época, o que lhes concede o direito de utilizar a área excedente de Reserva Legal para esses fins. Para isso é necessário primeiramente que os mesmos realizem o Cadastro Ambiental Rural CAR e instituam instrumento ou termo de servidão ambiental firmado perante órgão integrante do Sistema Nacional de Meio Ambiente - SISNAMA.

\section{CONSIDERAÇÕES FINAIS}

As técnicas de classificação orientada ao objeto foram de fundamental importância na análise de parâmetros institucionais de conservação florestal, o que permitiu concluir que, embora a área total das 24 propriedades rurais ainda seja relativamente pequena, 92,5\% dessas áreas estão cobertas por fitofisionomias arbóreas em estágio intermediário ou avançado de sucessão - sendo $81,4 \%$ somente no estágio avançado -, mesmo com o forte efeito de borda que ocorre em função do grande número de pastagens no entorno dessas propriedades.

Foi possível verificar características comuns quanto à cobertura de vegetação nativa das propriedades, associadas ao seu entorno e ao efeito de borda que estão submetidas. Nas de maior isolamento, seja por pastagens e/ou por cultivos agrícolas monoculturais, os percentuais de cobertura arbórea dominante foram menores $(3,7,8,15,16,18,19,2023)$, salvo raras exceções $(2,24)$, enquanto que nas que se inserem em fragmentos florestais maiores essa mesma taxa atingiu valores acima de $80 \%(1,5,6$, $10,12,14,21,22)$.

Os resultados confirmaram também o cumprimento das normas ambientais vigentes nesses territórios, sendo que as áreas de ocupação e uso consolidadas foram anteriores a 22 de Julho de 2008, como ampara a legislação atual. As imagens de satélite históricas possibilitaram a verificação de que boa parte das áreas de ocupação consolidadas nas propriedades já existia antes mesmo da aquisição das propriedades por esses grupos. Essa conservação tem se dado de maneira espontânea e não é somente por força da lei que essas instituições têm conduzido suas práticas de gestão e manejo de baixo impacto ambiental.

Em suma, a expansão territorial ayahuasqueira mostrou que está relacionada à manutenção de áreas florestadas e/ou destinadas ao cultivo das espécies ritualísticas em sistemas agroflorestais, como também à recuperação de áreas degradadas a partir de adensamentos e restauração florestal. Seus arranjos institucionais apresentaram relações de êxito em termos de conservação, embora ainda possam ser aprimoradas, e trazem em seu caráter religioso novos paradigmas na relação homem/natureza para sociedade urbana.

\section{REFERÊNCIAS}

BAATZ, M.; SCHÄPE, A. Multiresolution segmentation: an optimization approach for high quality multi-scale image segmentation. Journal of Photogrammetry and Remote Sensing, v. 58, p. 12-23, 2000.

BERNARDINO-COSTA, J.; SILVA, F. M. da. Construindo o mundo da hoasca: a organização da União do Vegetal. In: BERNARDINO-COSTA, J. (Org.). Hoasca: ciência, sociedade e meio ambiente. Campinas: Mercado de letras, 2011, p. 21-42.

BRASIL. Lei n. 12.651, de 25 de maio de 2012. Diário Oficial da União: República Federativa do Brasil: Poder Legislativo, Brasília, DF, 28 de maio de 2012a. Disponível em: <http://www.planalto.gov.br/ccivil_03/_ato20112014/2012/lei/l12651.htm>. Acesso em: 03 nov. 2016.

Lei n. 12.727 de 17 de outubro de 2012. Diário Oficial da União: República Federativa do 


\section{USO E COBERTURA DA TERRA NO TERRITÓRIO AYAHUASQUEIRO EM RONDÔNIA: UMA ANÁLISE DE ARRANJOS INSTITUCIONAIS POR CLASSIFICAÇÃO ORIENTADA A OBJETO}

Brasil: Poder Legislativo, Brasília, DF, 18 de outubro de 2012b. Disponível em: <http://www.planalto.gov.br/ccivil_03/_ato20112014/2012/lei/L12727.htm>. Acesso em: 09 de nov. 2016

BROWN, J. C. Development in Rondônia, Brazil 1980-1990. POLONOROESTE, Nongovernmental Organizations (NGOs) and the World Bank. M. A. Thesis, Lawrence: University of Kansas, 1992.

CHUBEY, M. S.; FRANKLIN, S. E.; WULDER, M. A. Object-based analysis of Ikonos-2 imagery for extraction of forest inventory parameters. Photogrammetric Engineering \& Remote Sensing, v. 72 , n. 4, p. 383-394, 2006.

FERREIRA, L. V.; LAURANCE, W. F. Effects of forest fragmentation on mortality and damage of selected trees in central Amazonia. Conservation Biology, n. 11, p. 797-801, 1997.

INPE. Projeto PRODES: Monitoramento da Floresta Amazônica Brasileira por Satélite. Disponível em:

http://www.obt.inpe.br/prodes/index.php>.

Acesso em: 08 de abr. 2017.

KAPOS, V.; WANDELLI, E.; CAMARGO, J. L.; GANADE, G. Edge-related changes in environment and plant responses due to forest fragmentation in central Amazonia. In: LAURANCE W. F.; BIERREGAARD R. O. (Eds). Tropical forest remnants: ecology, management, and conservation of fragmented communities. University of Chicago Press, Chicago, 1997, p. 3344.

KERAMITSOGLOU, I.; KONTOES, C.; SIFAKIS, N.; MITCHLEY, J.; XOFIS, P. Kernel based reclassification of Earth observation data for fine scale habitat mapping. Journal for Nature Conservation, n. 13, p. 91-99, 2005.

LANDAU, E. C.; CRUZ, R. K. da; HIRSCH, A.; PIMENTA, F. M.; GUIMARÃES, D. P. Variação Geográfica do Tamanho dos Módulos Fiscais no Brasil. Sete lagoas: Embrapa Milho e Sorgo, Doc. 146, 2012.

LAURANCE, W. F.; LOVEJOY, T. E.; VASCONCELOS, H. L.; BRUNA, E. M.; DIDHAM, R. K.; STOUFFER, P. C.; GASCON, C.; BIERREGAARD, R. O.; LAURANCE, S. G.; SAMPAIO, E. Ecosystem decay of Amazonian forest fragments: a 22-year investigation. Conservation Biology, n. 16, p. 605618, 2002.
LUZ, N. B. da; ANTUNES, A. F. B.; TAVARES JÚNIOR, J. B. Segmentação multirresolução e classificação orientada a objetos aplicados a imagens SPOT-5 para o mapeamento do uso da terra. Floresta, Curitiba, PR, v. 40, n. 2, p. 429446, 2010.

MAUSEL, P. et al. Spectral identification of successional stages following deforestation in the Amazon. Geocarto International, v. 8, n. 4, p. 6171, 1993.

MITRI, G.H.; GITAS, I. Z. A performance evaluation of a burned area object-based classification model when applied to topographically and nontopographically correct TM imagery. International Journal of Remote Sensing, v. 25, n. 14, p. 2863-2870, 2004.

MURCIA, C. Edge effects in fragmented forests: implications for conservation. Trends in Ecology and Evolution, n. 10, p. 58-62, 1995.

OLIVEIRA, S. J. de M.; BACHA, C. J. C. Avaliação do cumprimento da reserva legal no Brasil. Revista de Economia e Agronegócio, v. 1, n. 2, p. 177204, 2003.

PORTO-GONÇALVES, C. W. Amazônia, Amazônias. 2 ed. São Paulo: Contexto, 2005.

PRATT, W.K. Digital image processing: PIKS scientific inside. 4a ed. New York: J. Wiley, 2007.

ROCHA, A. D. Estabelecimento de Metodologia de Classificação de Imagens de Alta Resolução para Identificar e Avaliar o Crescimento e Áreas de Ocupação Irregular. 2007. Dissertação (Mestrado em Ciências Geodésicas) Universidade Federal do Paraná-UFPR, Curitiba.

RONDÔNIA. Lei Complementar n. 312, de 06 de maio de 2005. Diário Oficial do Estado de Rondônia: Poder Legislativo, Rondônia, n. 264, 10 maio $2005 . \quad$ Disponível em: <http://sapl.al.ro.leg.br/sapl_documentos/norma juridica/445_texto_integral>. Acesso em: $14 \mathrm{de}$ nov. 2016

ROSS, J. Ecogeografia do Brasil: subsídios para planejamento ambiental. São Paulo: Oficina de Textos, 2006.

SALATINO, A. Nós e as plantas: ontem e hoje. Rev. brasileira de Botânica, v. 24, n. 4, p. 483-490, 2001.

SKOLE, D. L. et al. Physical and Human Dimensions of Deflorestation in Amazonia. BioScience, v. 44, n. 5, p. 314-322, 1997. 


\section{USO E COBERTURA DA TERRA NO TERRITÓRIO AYAHUASQUEIRO EM RONDÔNIA: UMA ANÁLISE DE ARRANJOS INSTITUCIONAIS POR CLASSIFICAÇÃO ORIENTADA A OBJETO}

THEVENIN, J. M. R. A natureza nos caminhos de ayahuasca: territorialidade, arranjos institucionais e aspectos fitogeográficos de conservação florestal na Amazônia (Rondônia/Brasil). 2017. Tese (Doutorado em Geografia) - Universidade Estadual Paulista UNESP, Presidente Prudente.

TUCKER, C. M.; SOUTHWORTH, J. Processos de mudança florestal em nível local e de paisagem em Honduras e Guatemala. In: MORAN, E. F.; OSTROM, E. (Orgs.). Ecossistemas florestais: Interação homem-ambiente. São Paulo: Senac/Edusp, 2009, p. 327-354.
VERÍSSIMO, A.; ROLLA, A.; VEDOVETO, M.; FURTADA, S. de M. Áreas Protegidas na Amazônia Brasileira: Avanços e Desafios. Belém: IMAZON; São Paulo: ISA, 2011.

YAN, G.; MAS, J. -F.; MAATHUIS, B.H.P.; XIANGMIN,Z.;VAN DIJK, P.M. Comparison of pixel-based and object-oriented image classification approaches- a case study in a coal fire area, Wuda, Inner Mongolia, China. International Journal of Remote Sensing, v. 27, n. 18-20, p. 4039-4055, 2006. 